\title{
The effect of physical exercise on the memory of elderly - an intervention study
}

\author{
Thuanne da Silva Santos ${ }^{1}$ id, Saulo Vasconcelos Rocha ${ }^{2}$ (iD, Lélia Renata Carneiro Vasconcelos ${ }^{2}$ (iD, Bruno \\ Morbeck de Queiroz ${ }^{3}$ (iD, Sabrina Correia de Oliveira ${ }^{1}$ (iD, Andrée Philippe Pimentel Coutinho ${ }^{4}$ iD \\ ${ }^{1}$ Universidade Estadual do Sudoeste da Bahia,Departamento de Saúde I, Jequié, BA, Brasil; ${ }^{2}$ Universidade \\ Estadual do Sudoeste da Bahia, Departamento de Saúde II, Jequié, BA, Brasil; ${ }^{3}$ Faculdade de Ciências e \\ Tecnologia, Vitória da Conquista, BA, Brasil; ${ }^{4}$ Universidade Federal de Santa Catarina, Florianópolis, SC, \\ Brasil
}

\begin{abstract}
Aim: To compare the effect that two programs of physical exercise have over the memory of elderly people. Methods: This was an intervention study conducted with 79 seniors of both sexes. Individuals included in the study were randomly assigned into two groups: aerobic exercise (39 individuals) and neuromotor exercise (40 individuals). Interventions: The aerobic exercise program consisted of walking activities. The neuromotor exercise program included activities for muscle strength, flexibility, balance, and agility. A total of 36 sessions were conducted with each one lasting approximately 50 minutes, 3 days a week for a period of 12 weeks, for both groups. Main outcomes and measures: The intensity of activity was controlled by the Borg scale (12-16). We evaluated memory performance through a list of figures. Means of the tests for memory performance were compared through Repeated Measures ( $\mathrm{p} \leq 0.05$ ). Results: After the intervention period, 44 individuals remained in the sample while 29 remained in the aerobic group and 15 in the neuromotor group. The average age of respondents was $68.81 \pm 7.12$ years. No significant differences were observed between groups when analyzing the interaction, time, and group according to memory tests. Significant improvements were identified after the intervention period in both groups for the variables nomination and incidental memory. Conclusion: Aerobic and neuromotor exercise programs led to an increase in the memory performance of the elderly in the functions appointment (short-term memory) and incidental memory (long-term memory).
\end{abstract}

Keywords: aging, motor activity, memory.

\section{Introduction}

The reduction of organic resistance, restriction of motor skills, increased physical limitations, and reduced cognitive functions are events that worsen with the advance of age ${ }^{1,2}$. Among the changes that are inherent to aging, the reduction of cognitive function appears as one of the impairments that most affect the quality of life of older people ${ }^{3}$.

Cognitive functions, particularly memory, can retain and store acquired information, enabling behavior change based on lifelong experience. This human faculty, physiologically, can be divided into two forms according to how information has been stored temporarily (short-term memory) or longer (long-term memory) $)^{4}$.

Memory decline is one of the most affected cognitive functions in the aging process $^{3}$, implying difficulties in performing daily activities, the ability to plan and perform tasks, as well as communication skills ${ }^{5,6}$. Given this situation, the literature has proposed several therapies to delay changes related to the loss of cognitive function in the elderly. Among these, physical exercise is a low cost and effective non-pharmacological alternative for memory prevention / rehabilitation, acting positively on cerebral angiogenesis, neurogenesis, and synaptogenesis ${ }^{7-13}$.
In this sense, regular exercise improves the performance of different cognitive tasks, such as processing speed, selective attention, and short and long-term memory ${ }^{14,15}$. Therefore, the mechanisms that guide these positive adaptations in exerciseinduced memory are related to increased regional blood flow and energy supply ${ }^{16}$, increased neurotransmitter activity ${ }^{16,17}$, adaptations in brain structures, and synaptic plasticity ${ }^{18}$.

The acute and chronic benefits of aerobic exercise in memory have been widely reported. These effects are acutely known to be possibly due to increased cerebral blood flow and neurotransmitter activity ${ }^{16}$. Chronically, it is speculated that aerobic exercise may promote adaptations in brain structures and synaptic plasticity that would culminate in cognitive improvements $^{11,17,19}$.

In addition to aerobic exercise, recent studies have shown that a neuromotor exercise program (eg endurance training) is inversely associated with long memory performance, although aerobic exercise has greater effects on brain-derived neurotrophic growth factor (BDNF). It is extraordinarily speculated that neuromotor exercise may have a greater effect on neural survival and neurogenesis compared to the aerobic exercise pro$\operatorname{gram}^{20,21}$. Therefore, both the aerobic exercise program and the 
neuromotor can induce the increase of these proteins in the brain, positively influencing the long-term related memory.

However, despite the growing number of studies that have assessed the relationship between exercise and cognition ${ }^{8,22-24}$, scarce evidence is available on the relationship dose-response of physical exercises, such as the neuromotor, and cognition and/or memory function ${ }^{8,25}$ of healthy seniors. In this sense, the objective of the present study was to evaluate and compare the effect that two programs of physical exercise have on the memory of elderly people.

\section{Methods}

\section{Trial design}

This is an intervention study, part of a project entitled "Effectiveness of an intervention program over the cognitive performance of elderly, which aims to evaluate the effectiveness of an exercise program on the cognitive performance of the elderly. The study was conducted in the city of Jequie from March to June 2015. This research followed the ethical principles stated in the Declaration of Helsinki and Resolution $n^{\circ} 466 / 12$ of the National Health Council. The research protocols were reviewed and approved by the Ethics Committee on Human Research of the State University of Southwest Bahia (CAAE: 22969013.0.0000.0055).

\section{Participants}

Recruitment of participants was conducted through disclosures in hospitals, Family Health Units (FHUs), groups, and ads in media outlets such as radio and the internet. Interested individuals received guidelines to carry out registrations in the Population Health Research Center (NESP) situated at the State University of Southwest Bahia (UESB).

The criteria for inclusion in the sample were individuals of both sexes aged at 60 years or older, with a medical certificate with permission to practice physical activity, who had not been practicing physical exercise programs for at least three months, and who reported not making use of medications that could influence cognitive performance.

The following exclusion criteria were considered: diagnosed with dementia or other cognitive changes that would compromise the accuracy of the information and attendance to the intervention program below $75 \%$.

After recruitment and prior assessment of the criteria for inclusion, 79 individuals aged 60 years and over, of both sexes remained in the sample. They were informed about the project objectives and were later randomized in the following intervention programs: Neuromotor exercise program X Aerobic exercise program (Figure 1).

Data collection started after approval from the Ethics Committee in Research of the UESB. The collection was divided into two stages, the first one week before the beginning of the intervention and the second shortly after the 12-week intervention. The initial assessment was performed before the randomization of participants. For the accomplishment of the

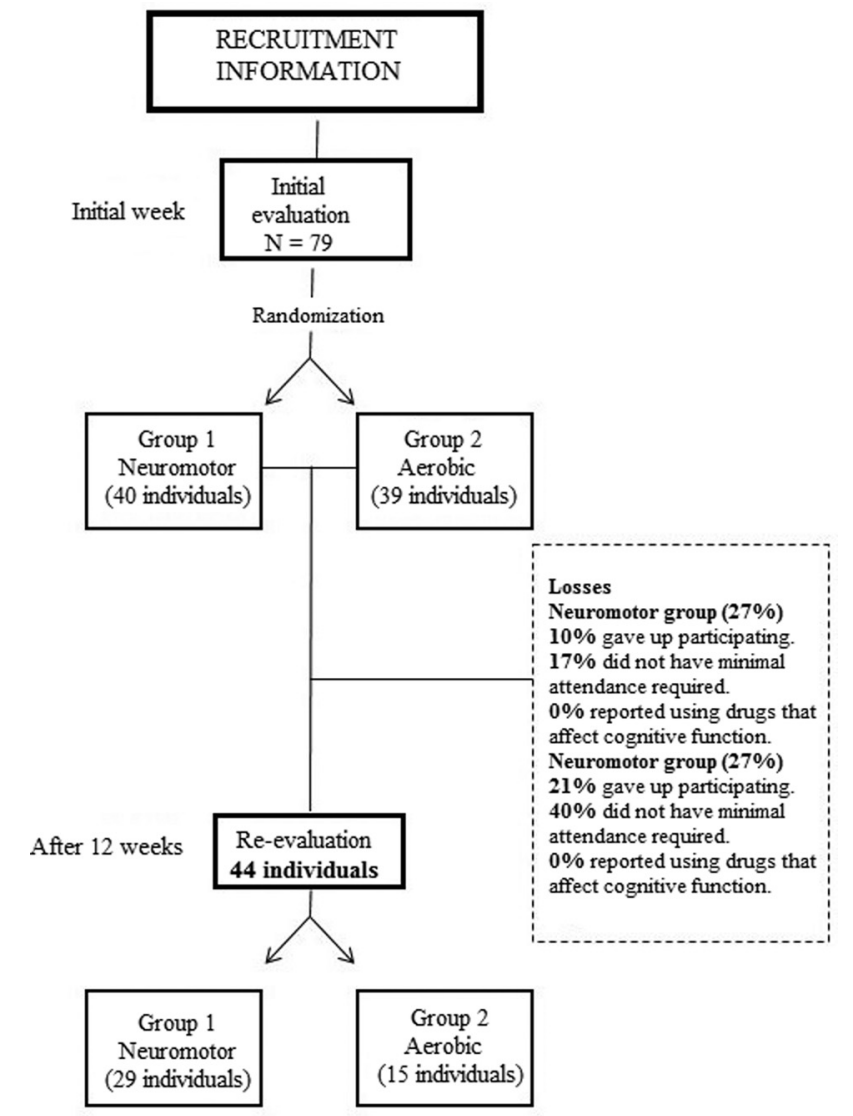

Figure 1 - Fluxorama of the study.

collection, the participant was invited to attend UESB during the days scheduled for data collection.

Participants were informed about the research, its importance, and its goals. After the participant's consent, this was interviewed individually through a questionnaire containing information on sociodemographic characteristics, and self-reported health status and tests for assessing memory.

\section{Intervention}

The intervention consisted of previously scheduled exercise sessions for three non-consecutive days a week and performed in groups with the help of a previously trained research team. Thirty-six exercise sessions were performed for 3 months (12 weeks).

Neuromotor exercise program: three weekly exercise sessions lasting 50 minutes each one and at moderate intensity were performed, keeping the level of 12 to 16 points on the Borg Scale of Perceived Exertion, which is equivalent to a heart rate of $120-160 \mathrm{bpm}^{26}$. The division of time was distributed between 4 modes of exercises ${ }^{18}$. Among these exercises were: Stretching and warming up exercises (10 minutes): active stretching and active-assisted muscle chains (30" per segment); active mobilization of large and small joints/body regions; light calisthenic exercises for warming up and activation of body muscles. Strengthening exercises (20 minutes): light resistance exercises with leggings, medicine ball, or elastic resistance (theraband or thera tube), with each exercise carried out in 4 series of 8 repeti- 
tions. Exercises of balance and functional activities $(10 \mathrm{~min}$ utes): functional gait training: circuit of obstacles (therabands, Hula hoops, small boxes, cones and rods); Stationary march associated with elevation and dissociation of members; Throwing and kicking the ball from one elderly person to the other, activities of standing up and sitting. Exercises of controlling breathing and muscle relaxation (10 minutes): respiratory and postural exercises: proprioception of respiratory muscles, diaphragmatic stimulation, prolonged inspiration, fractional breathing, massage in pairs, and dynamic of relaxation.

Aerobic exercise program: weekly sessions of 3 walks, lasting 25 to 30 minutes each one, and with moderate intensity were carried out. The intensity was monitored every 10 minutes and was kept at the level from 12 to 16 points in the Borg Scale of Perceived Exertion, which is equivalent to a heart rate of 120-160 bpm $^{26}$.

Stretching of various body segments before and after exercise (about 10 minutes) was realized. Furthermore, hydration was encouraged during activity breaks (after initial stretching, after walking and after the final stretching).

\section{Memory}

Memory was assessed using a set of tests proposed by ${ }^{27}$ named list of figures. This is an instrument that aims to evaluate the memory from six phases. In the first phase, the ability of perception and nomination is assessed. The score should be 10 points, and if there is more than one mistake then agnosia disorder is suggested ${ }^{27}$.

In the second phase, the incidental memory is assessed. The individual that reaches at least 5 points at this phase is considered normal ${ }^{27}$. In the third phase, the short-term memory is assessed. It is expected that in this phase healthy individuals obtain at least 7 points. Results below 5 indicate attention deficit ${ }^{27}$.

The fourth phase assesses the learning memory. The score for a normal individual is at least 7 points. Scores below that average have a relationship with the diagnosis of dementia or cognitive disorder ${ }^{27}$. In the fifth phase, it is possible to evaluate the long-term memory. The score for healthy individuals is up to 6 points and lower scores indicate a probability of a diagnosis of dementia or cognitive impairment ${ }^{27}$. The last phase evaluates the recognition of figures. The score for healthy individuals is 9 points $^{27}$.

\section{Intervening variables}

Socio-demographic characteristics and personal information: gender (male/female), age (years), marital status (married/common-lawmarriage/single/separated/widower), educational level (never went to school/reads and writes the name/elementary school I/elementary school II/high school/superior education), monthly income (in Brazilian reals), perceived health status (excellent/very good/fair/poor/does not know). Marital status was categorized in individuals with a partner (married and common-law marriage) and without a partner (single/divorced/separated/judiciously separated and widowers).

\section{Sample}

The following criteria were observed for calculation of sample size: 95\% confidence interval; Bilateral hypothesis testing; Significance level of 0.05 (type I error). The power of a test of $80 \%$ (type II error) for statistical analysis by ANOVA was adopted.

Initially, we calculated the effect size $(f)$ for the partial variance analysis of all participants and the performance in the test of figures (number of correct answers). Furthermore, two degrees of freedom and a power of $80 \%$ were adopted. It was determined that for moderate effect size $(0.5)$ and at confirming a minimal clinically significant difference, 15 participants in each group were necessary.

\section{Randomization}

Randomization was performed in parallel in the proportion of 1/1. Participants were allocated according to a list of randomization generated by the randomizer research program into two groups: aerobic exercise and neuromuscular exercise.

\section{Statistical analysis}

For analysis and interpretation of data, a confidence interval of $95 \%$ and a significance level of $5 \%(p \leq 0.05)$ were adopted. In the case of quantitative variables, descriptive analyses were carried out to characterize the sample and the values of the memory tests. In the case of qualitative variables, frequency distributions were applied. The comparison of the memory tests average was done through ANOVAs for repeated measures, which incorporates the dependence of observations. Data analysis was performed using the Statistical Package for Social Sciences (SPSS, version 22.0).

\section{Results}

We identified 80 individuals eligible for the study, 79 met the inclusion criteria and were randomized in two groups: aerobic exercise (39 subjects) and neuromotor exercise (40 subjects). Individuals who reported a lack of time or interest in participating in the project and those who had attendance below $75 \%$ of the total sessions were excluded from the analysis, as described in Figure 1. Forty-four individuals remained at the end of the study, 15 in the aerobic group and 29 in the neuromotor group.

The sample loss may have influenced the results. However, it is observed in the literature that the sample losses of the present study are close to those presented in other clinical trials with the same characteristics ${ }^{28}$.

The characteristics of the study participants about the state of health and sociodemographic conditions by the group are shown in Table 1. The age ranged from 60 to 75 years, the average was $66.6 \pm 6.0$ years for the aerobic exercise group and $69.7 \pm 6.6$ years for the neuromotor exercise group. Most participants in both groups are literate and live with companions. The average monthly income of participants was 724.00 \pm 1448.00 Brazilian reals. As for the perception of health status, 59.1\% of 
Table 1 - Characterization of participants per group. Jequié-BA, 2015.

\begin{tabular}{|c|c|c|c|c|c|c|}
\hline \multirow{3}{*}{ Variable } & \multicolumn{4}{|c|}{ Groups } & & \\
\hline & \multicolumn{2}{|c|}{ Neuromotor } & \multicolumn{2}{|c|}{ Aerobic } & \multicolumn{2}{|c|}{ Total } \\
\hline & $\mathbf{N}$ & $\%$ & $\mathbf{N}$ & $\%$ & $\mathbf{N}$ & $\%$ \\
\hline \multicolumn{7}{|l|}{ Gender } \\
\hline Male & 2 & 6.9 & 2 & 13.3 & 4 & 9.1 \\
\hline Female & 27 & 93.1 & 13 & 86.7 & 40 & 90.9 \\
\hline \multicolumn{7}{|l|}{ Level of education } \\
\hline No education & 3 & 10.3 & 1 & 6.7 & 4 & 9.1 \\
\hline Reads and writes their name & 3 & 10.3 & 0 & 0.0 & 3 & 6.8 \\
\hline Elementary school I & 11 & 37.9 & 8 & 53.3 & 19 & 43.2 \\
\hline Elementary school II & 4 & 13.8 & 1 & 6.7 & 5 & 11.4 \\
\hline High school & 6 & 20.7 & 2 & 13.3 & 8 & 18.2 \\
\hline Superior education & 2 & 6.9 & 3 & 20.0 & 5 & 11.4 \\
\hline \multicolumn{7}{|l|}{ Marital situation } \\
\hline With companion & 22 & 75.9 & 13 & 86.7 & 35 & 79.5 \\
\hline Without partner & 7 & 24.1 & 2 & 13.3 & 9 & 20.5 \\
\hline \multicolumn{7}{|l|}{ Monthly Income } \\
\hline $\mathrm{R} \$ 724-1448$ & 13 & 44.8 & 5 & 33.3 & 18 & 69.2 \\
\hline $\mathrm{R} \$ 1448-3380$ & 2 & 6.9 & 4 & 26.7 & 6 & 23.1 \\
\hline$\geq \mathrm{R} \$ 3680$ & 2 & 6.9 & 9 & 60.0 & 2 & 7.7 \\
\hline \multicolumn{7}{|c|}{ Perception of the state of health } \\
\hline Positive & 10 & 34.5 & 8 & 53.3 & 18 & 40.9 \\
\hline Negative & 19 & 65.5 & 7 & 46.7 & 26 & 59.1 \\
\hline
\end{tabular}

subjects reported to perceive their health as fair or poor (Table 1).

Table 2 shows the values of test $F$, significance and effect size to the results of the memory tests for the groups, time and interaction. There were significant values for the time of intervention in the variables nomination and incidental memory. A trend was observed in the time for the variables perception and shortterm memory 1 . No significant differences were found between the groups, neither was significant the interaction between time and time and group, in the memory tests evaluated. As for the effect size, values classified as small were observed, even considering the time, the group, and the interaction.

Mean values and standard deviation for the memory test (List of figures) are shown in Table 3. Significant differences were observed between the time of intervention for the variable's nomination and incidental memory for both groups according to the SIDAK test.

Table 2 - Values of the effect size $\left(d^{2}\right), \mathrm{F}$ and $\mathrm{P}$ value for memory tests evaluated between the groups, time of intervention and interaction.

\begin{tabular}{|c|c|c|c|c|c|c|c|c|c|}
\hline \multirow[b]{2}{*}{ Memory test } & \multicolumn{3}{|c|}{ Group } & \multicolumn{3}{|c|}{ Time } & \multicolumn{3}{|c|}{ Time * Group } \\
\hline & $d^{2}$ & $\mathbf{F}$ & $\mathbf{P}$ & $d^{2}$ & $\mathbf{F}$ & $\mathbf{P}$ & $d^{2}$ & $\mathbf{F}$ & $\mathbf{P}$ \\
\hline Perception & 0.02 & 1.05 & 0.310 & 0.06 & 2.98 & 0.091 & 0.06 & 2.98 & 0.090 \\
\hline Nomination & 0.01 & 0.56 & 0.459 & 0.14 & 6.56 & 0.014 & 0.07 & 3.17 & 0.083 \\
\hline Incidental memory & 0.02 & 0.82 & 0.370 & 0.35 & 21.7 & 0.001 & 0.02 & 0.92 & 0.344 \\
\hline Short-term memory 1 & 0.01 & 0.40 & 0.530 & 0.07 & 3.33 & 0.075 & 0.01 & 0.49 & 0.489 \\
\hline Short-term memory 2 & 0.01 & 0.36 & 0.553 & 0.01 & 0.05 & 0.824 & 0.01 & 0.05 & 0.824 \\
\hline Long-term memory & 0.01 & 0.19 & 0.663 & 0.01 & 0.25 & 0.620 & 0.02 & 0.67 & 0.418 \\
\hline Recognition & 0.01 & 0.51 & 0.480 & 0.06 & 2.61 & 0.114 & 0.01 & 0.04 & 0.839 \\
\hline
\end{tabular}


Table 3 - Mean values and standard deviation for the scores of the memory test for the aerobic exercise group and neuromotor exercise group, pre-and post-intervention, Jequié-BA, 2015.

\begin{tabular}{|c|c|c|}
\hline \multirow[b]{2}{*}{ Variables } & \multicolumn{2}{|l|}{ Time } \\
\hline & $\operatorname{Pre}$ Mean \pm SD & Post Mean \pm SD \\
\hline \multicolumn{3}{|c|}{ Perception score } \\
\hline Walking & $10.00 \pm 0.00^{\mathrm{Aa}}$ & $10.00 \pm 0.00^{\mathrm{Aa}}$ \\
\hline Neuromotor & $9.69 \pm 0.96^{\mathrm{Aa}}$ & $9.86 \pm 0.74^{\mathrm{Aa}}$ \\
\hline \multicolumn{3}{|c|}{ Nomination score } \\
\hline Walking & $9.80 \pm 0.56^{\mathrm{Aa}}$ & $9.87 \pm 0.51^{\mathrm{Ab} *}$ \\
\hline Neuromotor & $9.44 \pm 1.086^{\mathrm{Aa}}$ & $9.83 \pm 0.92^{\mathrm{Ab}^{*}}$ \\
\hline \multicolumn{3}{|c|}{ Incidental memory } \\
\hline Walking & $6.93 \pm 1.71^{\mathrm{Aa}}$ & $8.13 \pm 2.53^{\mathrm{Ab} *}$ \\
\hline Neuromotor & $5.97 \pm 2.09^{\mathrm{Aa}}$ & $8.00 \pm 1.49^{\mathrm{Ab} *}$ \\
\hline \multicolumn{3}{|c|}{$\begin{array}{l}\text { Short-term memory } \\
1\end{array}$} \\
\hline Walking & $8.33 \pm 1.34^{\mathrm{Aa}}$ & $9.13 \pm 1.12^{\mathrm{Aa}}$ \\
\hline Neuromotor & $8.03 \pm 1.91^{\mathrm{Aa}}$ & $8.68 \pm 2.01^{\mathrm{Aa}}$ \\
\hline \multicolumn{3}{|c|}{$\begin{array}{l}\text { Short-term memory } \\
2\end{array}$} \\
\hline Walking & $9.20 \pm 1.14^{\mathrm{Aa}}$ & $9.27 \pm 0.96^{\mathrm{Aa}}$ \\
\hline Neuromotor & $8.97 \pm 1.59^{\mathrm{Aa}}$ & $8.97 \pm 1.72^{\mathrm{Aa}}$ \\
\hline \multicolumn{3}{|c|}{ Long-term memory } \\
\hline Walking & $8.87 \pm 1.35^{\mathrm{Aa}}$ & $9.14 \pm 1.027^{\mathrm{Aa}}$ \\
\hline Neuromotor & $8.79 \pm 2.12^{\mathrm{Aa}}$ & $8.72 \pm 1.92^{\mathrm{Aa}}$ \\
\hline \multicolumn{3}{|l|}{ Recognition } \\
\hline Walking & $10.00 \pm 0.00^{\mathrm{Aa}}$ & $9.73 \pm 0.79^{\mathrm{Aa}}$ \\
\hline Neuromotor & $9.86 \pm 0.51^{\mathrm{Aa}}$ & $9.66 \pm 0.85^{\mathrm{Aa}}$ \\
\hline
\end{tabular}

Note. ${ }^{*}$ Capital letters show no statistical difference $(5 \%)$ between the groups; same lowercase letters show no statistical difference $(5 \%)$ between times, Sidak test.

\section{Discussion}

To our knowledge, this is the first study to compare the effects of aerobic and neuromotor programs of exercise over memory function (using a list of figures as an evaluation tool) of the elderly undiagnosed with cognitive impairment. The results of this study indicate that physical exercise of any modality (aerobic or neuromotor), even being short-term (12 weeks) and with moderate intensity can positively influence the performance of the memory of the elderly, particularly the functions related to the nomination and incidental memory. Contributions of physical exercise in memory have been documented in the literature as an important strategy for healthy aging ${ }^{29-33}$.

Participation in physical exercise programs can increase the performance of functions related to long-term memory(nomination $)^{34}$. This ability is essential for the development of oral and written language and its commitment is related to the difficulty in recognizing objects ${ }^{34,35}$ compromising the quality of life of elderly people.

The progress observed in nomination after exposure to exercise is due to neural stimulation in brain areas such as frontal and temporal cortex ${ }^{31,32}$. Best performances resulting from the exercise in this type of memory have been identified as predictors of preservation of the general cognitive ability ${ }^{33}$.

In a randomized clinical trial with the elderly who are at an increased risk for Alzheimer's, it was found that an aerobic exercise program of short duration (12 weeks) and moderate intensity increased the performance of nomination and working memory (incidental memory) ${ }^{33}$. Other studies that have used aerobic exercise programs to check the effect over the memory of the elderly showed similar results to the present study ${ }^{36-38}$.

A study of 119 elderly with an average age of 74.4 years found no effect of strength training (leg press, knee extension, hip abduction, and rowing) of short duration (12 weeks) on incidental memory when compared with control, who participated in lectures on education and health ${ }^{39}$. It is noteworthy that the incidental memory is part of a set of mental operations that are essential for the processing of short-term memory ${ }^{8,40}$ and its deterioration can cause difficulties for the storage of information and the ability to use them for understanding language, learning, and reasoning ${ }^{35,41,42}$.

It is known that physical exercise is effective to reverse the loss of volume of the prefrontal and parietal cortex in elderly people, and may have a reflection over the improvement of this function $^{6,31,41,43}$. Moreover, the mechanisms that contribute to decreased cognitive function and psychiatric disorder may be linked to the higher level of activity-induced BDNF, increasing neurogenesis and synaptogenesis ${ }^{13}$. In addition, the main physiological hypotheses that may explain the acute effects of regular exercise memory improvement are linked to increased regional blood flow and energy expenditure, leading to higher energy demand in areas of the cortex responsible for motor control $^{15,16,37,42}$. Therefore, it is possible to speculate that this flow redistribution is related to better performance in cognitive tasks.

The literature has reported that improvement in physical fitness standards is inversely associated with brain activation. These changes in brain structures, neurogenesis, and greater synaptic plasticity can be explained by hormonal mechanisms. Hormones such as Insulin Growth Factor I (IGF-I) and Vascular Endothelial Growth Factor (VEGF) are speculated to perform neuronal growth and stimulation functions ${ }^{13,20,44}$. Therefore, understanding the effects of physical training on hormone production is relevant in understanding the central nervous system adaptation to training.

In fact, IGF-1 and VEGF may explain the benefits of chronic exercise on memory performance. In addition, high serum IGF-I concentrations are known to have low plasma concentrations of homocysteine, a sulfur amino acid derived from methionine demethylation, and which at high levels may cause brain damage and neuropsychiatric disorders ${ }^{22,45,46}$.

The results of the present study should be analyzed with caution and some limitations should be taken into consideration. The evaluation was performed through only one instrument (List 
of figures). However, this instrument was previously validated $^{32}$. Still, the short time of intervention may have been another aspect that influenced the results, since a longer intervention can influence more comprehensively the cognition of the elderly ${ }^{41}$. On the other hand, the literature suggests that benefits can be observed in some cognitive functions in a period of three months $^{30,33}$.

However, the present study used a control group with an exercise program with effects established in the literature and adopted precise criteria for the inclusion and selection of participants, ensuring the homogeneity of the study sample.

\section{Conclusion}

The results of the present study indicate that physical exercise (aerobic and neuromotor) of short duration (12 weeks) has a positive effect on the memory of elderly people, particularly for the functions nomination and incidental memory. Thus, these findings provide support for the preparation of health actions directed at the elderly population, seeking to encourage increased level of physical activity in this population.

\section{References}

1. Dias RG, Streit IA, Sandreschi PF, Benedetti TRB, Mazo GZ. Diferenças nos aspectos cognitivos entre idosos praticantes e não praticantes de exercício físico. J Bras Psiquiatr. 2014;63(4):326331. doi.org/10.1590/0047-2085000000041

2. Santos PL, Foroni PM, Chaves MCF. Atividades físicas e de lazer e seu impacto sobre a cognição no envelhecimento. Medicina (Ribeirao Preto). 2009;42(1):54-60.

3. Cordeiro J, Del Castillo BL, de Freitas CS, Gonçalves MP. Efeitos da atividade física na memória declarativa, capacidade funcional e qualidade de vida em idosos. Rev bras geriatr Gerontol. 2014;17(3):541-52. doi.org/10.1590/1809-9823.2014.13006

4. Magila MC, Xavier GF. Modelos de sistemas de memória de longa duração em humanos. Psic Teor Pesq 1999;15(1):37-44.

5. Chiari H, de Mello MT, Rezeak P, Antunes HKM. Exercício físico, atividade física e os benefícios sobre a memória de idosos. Rev. Psicol e Saude. 2010;2(1). doi.org/10.20435/pssa.v2i1.34

6. Evers A, Klusmann V, Schwarzer R, Heuser I. Improving cognition by adherence to physical or mental exercise: A moderated mediation analysis. Aging Ment Health. 2011;15(4):446-455. doi.org/10.1080/13607863.2010.543657

7. Coelho FGDM, Vital TM, Novais IDP, Costa GDA, Stella F, Santos-Galduroz RF. Desempenho cognitivo em diferentes níveis de escolaridade de adultos e idosos ativos. Rev. Bras Geriatr Gerontol. 2012;15(1):7-15. doi.org/10.1590/S180998232012000100002

8. Merege Filho CAA, Alves CRR, Sepúlveda CA, Costa AdS, Lancha Junior AH, Gualano B. Influência do exercício físico na cognição: uma atualização sobre mecanismos fisiológicos. 2014; Rev bras med esporte. 20(3), 237-241. doi.org/10.1590/151786922014200301930

9. Vargas LDS, Lara MVS, Mello-Carpes PB. Influência da diabetes e a prática de exercício físico e atividades cognitivas e recreativas sobre a função cognitiva e emotividade em grupos de terceira idade. Rev. Bras. Geriatr. Gerontol. 2014;17(4):867-78.

10. Spirduso WW. Physical fitness, aging, and psychomotor speed: a review. J Gerontol. 1980;35(6):850-865.
11. Hillman CH, Erickson KI, Kramer AF. Be smart, exercise your heart: exercise effects on brain and cognition. Nat. Rev. Neurosci. 2008;9(1):58-65.

12. Heisz JJ, Clark IB, Bonin K, Paolucci EM, Michalski B, Becker $\mathrm{S}$, et al. The effects of physical exercise and cognitive training on memory and neurotrophic factors. J Cogn Neurosci. 2017;29(11):1895-1907. doi.org/10.1162/jocn_a_01164

13. Kurdi FN, Flora R. The Impact of Physical Exercise on BrainDerived Neurotrophic Factor (BDNF) Level in Elderly Population. OpenAccessMaced J Med Sci. 2019;7(10):1618. doi:10.3889/oamjms.2019.337

14. McMorris T, Sproule J, Turner A, Hale BJ. Acute, intermediate intensity exercise, and speed and accuracy in working memory tasks: a meta-analytical comparison of effects. Physiol Behav. 2011;102(3-4):421-428.doi.org/10.1016/j.physbeh.2010.12.007

15. Lambourne K, Tomporowski P. The effect of exercise-induced arousal on cognitive task performance: a meta-regression analysis. Brain Res. 2010;23(1341):12-24. doi.org/10.1016/j.brainres.2010.03.091

16. Andres RH, Ducraya AD, Schlattner U, Wallimann T, Widmer HR. Functions and effects of creatine in the central nervous system. Brain Res Bull. 20081;76(4):329-343. doi.org/10.1016/j.brainresbull.2008.02.035

17. Watson P, Shirreffs SM, Maughan RJ. Blood-brain barrier integrity may be threatened by exercise in a warm environment. Am J Physiol-Reg I. 2005;288(6):R1689-R1694. doi.org/10.1152/ajpregu.00676.2004

18. Bushman B, Medicine ACoS. ACSM's Complete Guide to Fitness \& Health, 2E: Human Kinetics; 2017.

19. Chmura J, Nazar K, Kaciuba-Uscilko H. Choice reaction time during graded exercise in relation to blood lactate and plasma catecholamine thresholds. Int J Sports Med. 1994;15(4):172-176. doi: $10.1055 / \mathrm{s}-2007-1021042$

20. Iuliano E, Fiorilli G, Aquino G, Di Costanzo A, Calcagno G, di Cagno A. Twelve-week exercise influences memory complaint but not memory performance in older adults: A randomized controlled study. JAgingPhys Act. 2017;25(4):612-620. doi.org/10.1123/japa.2016-0249

21. Dunsky A, Abu-Rukun M, Tsuk S, Dwolatzky T, Carasso R, Netz Y. The effects of a resistance vs. an aerobic single session on attention and executive functioning in adults. PloS one. 2017;12(4):e0176092. doi.org/10.1371/journal.pone.0179799.

22. Guimarães AV, Rocha SV, Barbosa AR. Exercício físico e desempenho cognitivo em idosos: revisão sistemática. Medicina (Ribeirao Preto Online). 2014;47(4):377-386. doi.org/10.11606/issn.2176-7262.v47i4p377-386

23. Liu-Ambrose T, Nagamatsu LS, Voss MW, Khan KM, Handy TC. Resistance training and functional plasticity of the aging brain: a 12-month randomized controlled trial. Neurobiol Aging. 2012;33(8):1690-1698.

doi.org/10.1016/j.neurobiolaging.2011.05.010

24. Sofi F, Valecchi D, Bacci D, Abbate R, Gensini GF, Casini A, et al. Physical activity and risk of cognitive decline: a meta-analysis of prospective studies. j intern med. 2011;269(1):107-117. doi.org/10.1111/j.1365-2796.2010.02281.x

25. Coelho FGDM, Vital TM, Novais IDP, Costa GDA, Stella F, Santos-Galduroz RF. Desempenho cognitivo em diferentes níveis de escolaridade de adultos e idosos ativos. Rev. Bras Geriatr Gerontol. 2012;15(1):7-15. doi.org/10.1590/S180998232012000100002

26. Borg GA, Noble BJ. Perceived exertion. Exerc Sport Sci Rev. 1974;2(1):131-154. https://journals.lww.com/acsm-essr/Citation/1974/00020/Perceived_Exertion.6.aspx 
27. Nitrini R, Caramelli P, Bottino C, Damasceno BP, Brucki SMD, Anghinah R. Diagnóstico de doença de Alzheimer no Brasil: avaliação cognitiva e funcional. Arq Neuropsiquiatr. 2005;63(3A):720-727.

28. Miot HA. Tamanho da amostra em estudos clínicos e experimentais. J Vasc Bras. 2011;10(4):275-278.

29. Baker LD, Frank LL, Foster-Schubert K, Green PS, Wilkinson $\mathrm{CW}, \mathrm{McTiernan} \mathrm{A}$, et al. Effects of aerobic exercise on mild cognitive impairment: a controlled trial. Arch Neurol. 2010;67(1):71-79. doi:10.1001/archneurol.2009.307.

30. Erickson K, Raji C, Lopez O, Becker J, Rosano C, Newman A, et al. Physical activity predicts gray matter volume in late adulthood The Cardiovascular Health Study. Neurology. 2010; 75(16), 1415-1422. doi.org/10.1212/WNL.0b013e3181f88359

31. Erickson KI, Miller DL, Weinstein AM, Akl SL, Banducci S. Physical activity and brain plasticity in late adulthood: a conceptual and comprehensive review. Ageing Res. 2012;3(1):6. doi.org/10.4081/ar.2012.e6

32. Kirk-Sanchez NJ, McGough EL. Physical exercise and cognitive performance in the elderly: current perspectives. Clin Interv Aging. 2014; 9:51. doi:10.2147/CIA.S39506

33. Smith JC, Nielson KA, Antuono P, Lyons J-A, Hanson RJ, Butts AM, et al. Semantic memory functional MRI and cognitive function after exercise intervention in mild cognitive impairment. J Alzheimers Dis. 2013;37(1):197-215. doi:10.3233/JAD-130467.

34. Fleury FO, Avila CRB, editors. Rapid naming, phonological memory and reading fluency in Brazilian bilingual students. CoDAS; 2015; 27(1): 65-72. doi.org/10.1590/23171782/20152014091.

35. Diniz AB, Guerra ERFDM, Soares RDM, Mariz JVB, Cattuzzo MT. Assessment of cognition, physical activity and physical fitness in elderly: A critical review. Estud Psicol (Natal). 2013;18(2):315-324.

36. Chang YK, Huang CJ, Chen KF, Hung TM. Physical activity and working memory in healthy older adults: an ERP study. Psychophysiology. 2013;50(11):1174-1182. doi.org/10.1111/psyp.12089

37. McMorris T, Sproule J, Turner A, Hale BJ. Acute, intermediate intensity exercise, and speed and accuracy in working memory tasks: a meta-analytical comparison of effects. Physiol Behav. 2011;102(3-4):421-428. doi.org/10.1016/j.physbeh.2010.12.007

38. Peiffer R, Darby LA, Fullenkamp A, Morgan AL. Effects of acute aerobic exercise on executive function in older women. $\mathrm{J}$ Sports Sci Med. 2015;14(3):574.

39. Kimura K, Obuchi S, Arai T, Nagasawa H, Shiba Y, Watanabe S, et al. The influence of short-term strength training on health- related quality of life and executive cognitive function. J Physiol Anthropol. 2010;29(3):95-101. doi.org/10.2114/jpa2.29.95

40. Mourão-Júnior CA, Melo LBR. Integração de três conceitos: função executiva, memória de trabalho e aprendizado. Psic: Teor e Pesq. 2011;3(27):309-314.

41. Klingberg T. Training and plasticity of working memory. Trends Cogn Sci. 2010;14(7):317-324. doi.org/10.1016/j.tics.2010.05.002

42. Soares R, Diniz AB, Cattuzzo MT. Associação entre atividade física, aptidão física e desempenho cognitivo em idosos. Motri. 2013;9(2):85-94

43. Nouchi R, Taki Y, Takeuchi H, Sekiguchi A, Hashizume H, Nozawa $T$, et al. Four weeks of combination exercise training improved executive functions, episodic memory, and processing speed in healthy elderly people: evidence from a randomized controlled trial. Age. 2014;36(2):787-799. doi:10.1007/s11357013-9588-x

44. Rhyu IJ, Bytheway JA, Kohler SJ, Lange H, Lee KJ, Boklewski $\mathrm{J}$, et al. Effects of aerobic exercise training on cognitive function and cortical vascularity in monkeys. Neuroscience. 2010;167(4): 1239-1248. doi.org/10.1016/j.neuroscience.2010.03.003

45. Ducloux D, Motte G, Nguyen NU, Abdelfatah A, Gibey R, Chalopin JM. Homocysteine, nutritional status and insulin in renal transplant recipients. Nephrol Dial Transplant. 2002;17(9):1674-1677. doi.org/10.1093/ndt/17.9.1674

46. Van Praag H, Kempermann G, Gage FH. Running increases cell proliferation and neurogenesis in the adult mouse dentate gyrus.Nat Neurosci. 1999;2(3):266-270.

\section{Corresponding author}

Saulo Vasconcelos Rocha

Universidade Estadual do Sudoeste da Bahia, Rua José Moreira Sobrinho, s/n, Jequiezinho, CEP 45206-190.

Jequié, BA, Brasil.

E-mail: svrocha@uesb.edu.br

Manuscript received on January 26, 2019

Manuscript accepted on October 24, 2019

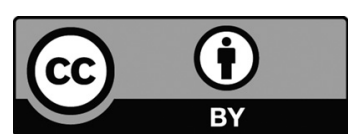

Motriz. The Journal of Physical Education. UNESP. Rio Claro, SP, Brazil eISSN: 1980-6574 - under a license Creative Commons - Version 4.0 